\title{
PEMODELAN MATEMATIKA PADA PERCABANGAN PEMBULUH DARAH
}

\author{
DELSIANA BONETA, EFENDI, MAHDHIVAN SYAFWAN \\ Program Studi S1 Matematika, \\ Fakultas Matematika dan Ilmu Pengetahuan Alam, Universitas Andalas, \\ Kampus UNAND Limau Manis Padang, Indonesia, \\ email : bonetadelsi@gmail.com
}

\begin{abstract}
Abstrak. Pada penelitian ini, dibahas pemodelan percabangan pada pembuluh darah sehingga diperoleh sudut optimal agar darah dapat mengalir dengan lancar didalam pembuluh. Pada pemodelan diperoleh resistensi dan volume dari fluida yang mana nilai minimum dari resistensi dan volume fluida akan mengoptimalkan aliran darah pada pembuluh darah. Disini juga diperiksa kesesuaian model yang diperoleh dengan hasil observasi Empiris Roux.
\end{abstract}

Kata Kunci: Pemodelan percabangan pembuluh darah, Resistensi, Volume Fluida, Observasi Empiris Roux

$\begin{array}{lll}\text { Diterima } & : & \text { 26 Juli 2018 } \\ \text { Direvisi } & : & 17 \text { September } 2018 \\ \text { Dipublikasikan } & : & 21 \text { Desember 2018 }\end{array}$

\section{Pendahuluan}

Sistem peredaran darah adalah suatu sistem organ yang berfungsi memindahkan zat dari sel ke sel. Sistem peredaran darah manusia merupakan suatu sistem pemindahan nutrisi dan zat-zat tertentu melalui sistem peredaran darah dari jantung ke seluruh sel-sel organ dalam tubuh dan begitu pula sebaliknya. Bagian dari sistem sirkulasi yang mengangkut darah ke seluruh tubuh adalah pembuluh darah [1].

Pada tahun 1878 Wilhelm Roux [5] membahas hubungan antara sudut dan jarijari percabangan pembuluh darah dengan menggunakan beberapa prinsip sederhana. Untuk memperoleh kembali hasil dari Roux akan diturunkan model percabangan pembuluh darah melalui eksplorasi yang dikaji oleh John Adam [1].

Dalam memodelkan percabangan pembuluh darah, hal pertama yang menjadi perhatian adalah sifat alami dari fluida. Newton memodelkan jenis fluida sederhana dengan menganggap fluida tersebut terdiri dari lapisan-lapisan tipis yang saling bergesekan satu sama lain sehingga menghasilkan resistensi(hambatan) pada arus fluida. Tingkat resistensi suatu fluida diukur berdasarkan viskositas dari fluida tersebut. Semakin besar viskositas suatu fluida, maka semakin besar tingkat resistensi yang terjadi pada fluida tersebut. Pada penelitian ini akan diturunkan model percabangan pada pembuluh darah sehingga diperoleh sudut optimal agar darah dapat mengalir dengan lancar dalam pembuluh darah. Selanjutnya akan diperiksa kesesuaian model terhadap hasil observasi empiris yang dilakukan oleh 
Roux. Penelitian ini mengekplorasi kembali kajian yang dilakukan oleh John Adam $[1]$.

\section{Observasi Empiris Roux}

Untuk memilih model terbaik dari percabangan pembuluh darah, model-model yang telah didapatkan pada pemodelan percabangan pembuluh darah dapat dibandingkan dengan hasil observasi empiris Roux. Roux memberikan sekumpulan observasi empiris tentang percabangan vaskuler (dikutip terpisah dari Thompson [6] dan Rosen [4]), yang diuraikan sebagai berikut.

1. Jika sebuah arteri terbagi dalam dua cabang yang sama besar, maka percabangan arteri tersebut memiliki sudut yang sama dari cabang utama.

2. Jika cabang-cabang tidak mempunyai radius yang sama, maka cabang yang radiusnya lebih besar menghasilkan sudut yang lebih kecil dibandingkan cabang yang mempunyai radius kecil.

3. Cabang-cabang dengan radius yang sangat kecil memiliki sudut percabangan yang besar (antara $70^{\circ}$ hingga $90^{\circ}$ ).

\section{Model Percabangan Pembuluh Darah}

Pada bab ini ditinjau terlebih dahulu kasus percabangan pembuluh darah kecil yang bercabang dari pembuluh darah yang lebih besar. Misalkan pembuluh darah tersebut lurus, perhatikan Gambar 1 berikut.

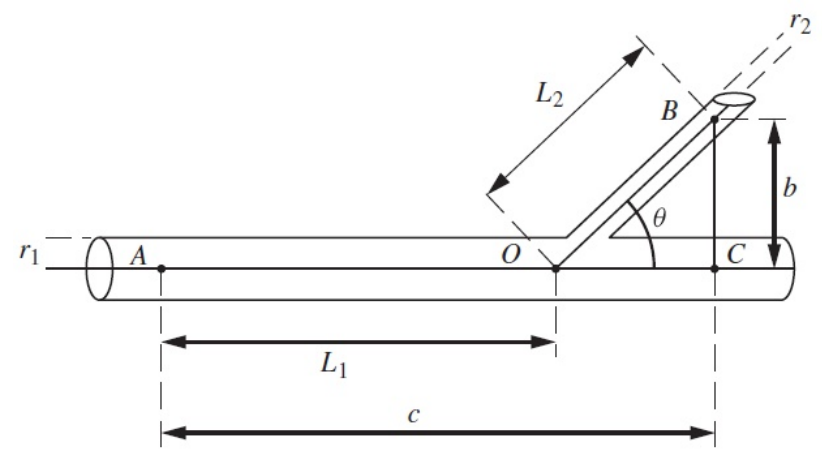

Gambar 1. Arteri pada percabangan pembuluh darah

Pada Gambar 1 ditampilkan konfigurasi dasar percabangan dimana pembuluh darah utama dengan radius $r_{1}$ memiliki cabang dengan radius $r_{2}$ dimana $r_{2}<r_{1}$ dan sudut percabangan $\theta \in(0, \pi / 2)$. Misalkan titik $A, B$, dan $C$ tetap, dengan jarak $c=|A C|$ dan $b=|C B|$. Besar sudut $\theta$ menentukan lokasi titik $O$ sehingga jarak $L_{1}=|A O|=c-b \cot \theta$ dan $L_{2}=|O B|=b \csc \theta$. Akan dihitung total resistensi hidrolik minimum sepanjang lintasan $A O B$ berdasarkan hukum Poiseuille dengan 
menggunakan persamaan $\mathcal{L}=\frac{\Delta P}{V}=\frac{8 \mu L}{\pi a^{4}} \propto a^{-4} L[1]$, yang menyatakan resistensi hidrolik sebanding dengan panjang saluran dan berbanding terbalik dengan pangkat empat dari radius setiap komponen sistem. Dengan demikian total resistensi dapat dinyatakan sebagai :

$$
\mathcal{L}_{1}=k\left[\frac{L_{1}}{r_{1}^{4}}+\frac{L_{2}}{r_{2}^{4}}\right]=k\left[\frac{c-b \cot \theta}{r_{1}^{4}}+\frac{b \csc \theta}{r_{2}^{4}}\right],
$$

dimana $k$ suatu konstanta positif. Untuk meminimalkan resistensi sebagai fungsi dari $\theta$, maka total resistensi diturunkan terhadap $\theta$ sebagai berikut:

$$
\frac{d \mathcal{L}_{1}}{d \theta}=\frac{k b}{r_{2}^{4}} \csc ^{2} \theta\left[\left(\frac{r_{2}}{r_{1}}\right)^{4}-\cos \theta\right] .
$$

Karena $k, b, \csc ^{2} \theta>0$, maka diperoleh titik kritis

$$
\theta_{m}=\cos ^{-1}\left(\frac{r_{2}}{r_{1}}\right)^{4}
$$

Selanjutnya substitusikan beberapa nilai relatif dari jari-jari untuk menguji model $\theta_{m}$ tersebut. Jika $r_{2}=0.5 r_{1}$, maka $\theta_{m} \approx 86^{\circ}$. Selanjutnya jika $r_{2}=0.8 r_{1}$, maka $\theta_{m} \approx 66^{\circ}$. Perhatikan bahwa sudut pertama yang didapatkan adalah $\theta_{m} \approx$ $86^{0}$, artinya $\theta_{m}$ hampir membentuk sudut siku-siku, yang mana hasil yang diperoleh tidak realistis dan belum sesuai dengan fenomena aliran darah yang ada. Hal ini disebabkan karena total resistensi hanya berhubungan dengan lintasan $A O B$, akibatnya efek $\theta_{m}$ pada lintasan $A O C$ menjadi diabaikan. Hal yang perlu diperhatikan adalah fungsi biaya yang juga berhubungan dengan lintasan $A O B$, karena fungsi biaya adalah suatu biaya yang dibutuhkan oleh sistem ketika melewati pipa.

Untuk meminimumkan total resistensi pada aliran, Roux dan Rosen mempertimbangkan untuk meminimumkan biaya pemeliharaan dari struktur pembuluh. Dalam hal ini masuk akal untuk mengasumsikan bahwa biaya pemeliharaan mestilah proporsional dengan volume dari sistem. Adapun volume fluida di sepanjang lintasan $A O B$ adalah

$$
\mathcal{L}_{2}=K\left[L_{1} r_{1}^{2}+L_{2} r_{2}^{2}\right],
$$

dimana $K$ adalah suatu konstanta positif. Untuk meminimumkan $\mathcal{L}_{2}$ sebagai fungsi dari $\theta$, maka $\mathcal{L}_{2}$ diturunkan terhadap $\theta$ sebagai berikut:

$$
\frac{d \mathcal{L}_{2}}{d \theta}=K b r_{2}^{2}\left(\csc ^{2} \theta\right)\left[\left(\frac{r_{1}}{r_{2}}\right)^{2}-\cos \theta\right] .
$$

Dengan demikian volume $\mathcal{L}_{2}$ akan minimum ketika

$$
\theta_{m}=\cos ^{-1}\left(\frac{r_{1}}{r_{2}}\right)^{2}
$$

yang mana tidak sama dengan nilai $\theta_{m}$ yang meminimumkan fungsi $\mathcal{L}_{1}$ sebelumnya. Untuk membuktikan $\theta_{m}$ merupakan titik yang meminimumkan $\mathcal{L}_{2}$, akan digunakan 
Uji Turunan Pertama seperti pada total resitensi hidrolik. Fungsi biaya selanjutnya memuat suku yang proposional terhadap resistensi dan suku yang proposional terhadap volume, sehingga diperoleh :

$$
\begin{aligned}
\mathcal{L} & =\mathcal{L}_{1}+\mathcal{L}_{2} \\
& =L_{1}\left(\frac{k}{r_{1}^{4}}+K r_{1}^{2}\right)+L_{2}\left(\frac{k}{r_{2}^{4}}+K r_{2}^{2}\right) .
\end{aligned}
$$

Misalkan $A_{1}=\left(\frac{k}{r_{1}^{4}}+K r_{1}^{2}\right)$ dan $A_{2}=\left(\frac{k}{r_{2}^{4}}+K r_{2}^{2}\right)$, maka persamaan terakhir dapat ditulis

$$
\mathcal{L}=L_{1} A_{1}+L_{2} A_{2}=(c-b \cot \theta) A_{1}+b \csc \theta A_{2} .
$$

\subsection{Model pada Pembuluh Darah Tunggal}

Pada bagian ini akan ditinjau $\mathcal{L}$ pada pembuluh darah tunggal yang tidak bercabang dengan radius $r$ dan panjang $L$, yaitu

$$
\mathcal{L}=k L r^{-4}+K L r^{2}
$$

Secara biologi, persamaan (3.6) menyatakan bahwa kontribusi pembuluh darah terhadap total biaya ditentukan berdasarkan dua faktor yang saling berkompetisi, yaitu daya yang mempertahankan volume darah yang mengisi pembuluh darah, dan daya yang dibutuhkan untuk memompa darah melalui pembuluh darah yang sama.

Jika sudut percabangan dapat meminimalisasi fungsi biaya, maka radius dari masing-masing pembuluh darah harusnya dapat meminimalisasi fungsi biaya juga. Dari Persamaan (3.6) diperoleh

$$
\frac{d \mathcal{L}}{d r}=\left(-4 k r^{-5}+2 K r\right) L
$$

Persamaan (3.7) minimum ketika $r=\sqrt[6]{\frac{2 k}{K}}$. Untuk membuktikan $r$ adalah titik yang meminimumkan $\mathcal{L}$ maka akan digunakan uji turunan kedua, sebagai berikut :

$$
\mathcal{L}^{\prime \prime}(r)=\left(\frac{20 k}{r^{6}}+2 K\right) L,
$$

karena $\left(\frac{20 k}{r^{6}}+2 K\right)>0$ dan $L>0$ maka $\mathcal{L}^{\prime \prime}(r)>0$ sehingga $\mathcal{L}(r)$ merupakan nilai minimum. Dengan mensubstitusikan $k=\frac{K r^{6}}{2}$ ke Persamaan (3.6) diperoleh nilai minimum

$$
\mathcal{L}=\beta L r^{2}
$$

setelah memisalkan $\beta=\frac{3 K}{2}$.

\subsection{Model pada Pembuluh Bercabang Dua (Bifurkasi)}

Pada fungsi biaya sebelumnya, percabangan yang digunakan adalah percabangan pembuluh darah yang kecil dari yang besar, bukan pada pembuluh darah yang bercabang dua (bifurkasi). Perhatikan Gambar 2. 


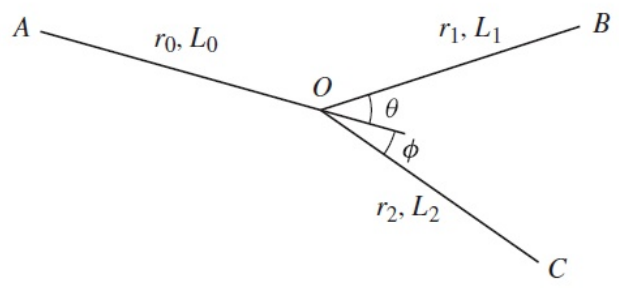

Gambar 2. Pembuluh bercabang dua (bifurkasi)

Pada Gambar 2 misalkan titik $A, B$ dan $C$ tetap. Titik $O$ menyatakan lokasi percabangan dengan sudut percabangan $\phi$ dan $\theta$. Jari-jari dan panjang dari pembuluh $O A, O B$ dan $O C$ masing-masing dinyatakan oleh $r_{0}, L_{0} ; r_{1}, L_{1} ;$ dan $r_{2}$, $L_{2}$. Dengan menggunakan persamaan (3.6) diperoleh total biaya minimum untuk pembuluh bercabang dua sebagai berikut:

$$
\mathcal{L}=\mathcal{L}_{A O}+\mathcal{L}_{O B}+\mathcal{L}_{O C}=\beta L_{0} r_{0}{ }^{2}+\beta L_{1} r_{1}{ }^{2}+\beta L_{2} r_{2}{ }^{2} .
$$

Selanjutnya akan ditinjau perubahan kecil pada lokasi percabangan titik $O$ ke titik $O^{\prime}$. Pada masing-masing kasus, jarak antara $O$ dan $O^{\prime}$ adalah $\delta$, yang nilainya kecil dibandingkan dengan jarak $A O, O B$, dan $O C$. Akan dilihat perubahan kecil pada titik $O$ ke $O^{\prime}$.

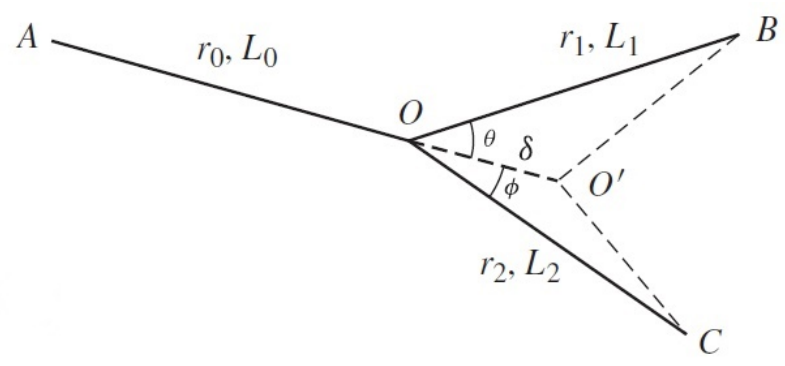

Gambar 3. Perubahan pertama pada konfigurasi pembuluh darah yang bercabang dua

Gambar 3 adalah perubahan pertama pada konfigurasi pembuluh darah yang bercabang dua. Dari gambar langsung diperoleh nilai $O^{\prime} A$, yaitu

$$
O^{\prime} A=L_{0}+\delta .
$$

Selanjutnya akan dicari nilai $O^{\prime} B$ dengan menggunakan Hukum Kosinus, dan anggap $\delta^{2}=0$, sehingga diperoleh:

$$
\begin{aligned}
& O^{\prime} B=L_{1} \sqrt{1-\frac{2 \delta}{L_{1}} \cos \theta} \approx L_{1}-\delta \cos \theta . \\
& O^{\prime} C=L_{2}-\delta \cos \phi .
\end{aligned}
$$


Selanjutnya akan digunakan Persamaan 3.9 untuk memperoleh total kenaikan biaya. Karena total kenaikan biaya pada $O^{\prime}$ sama dengan total biaya pada Persamaan 3.9, sehingga diperoleh

$$
r_{0}^{2}=r_{1}^{2} \cos \theta+r_{2}^{2} \cos \phi .
$$

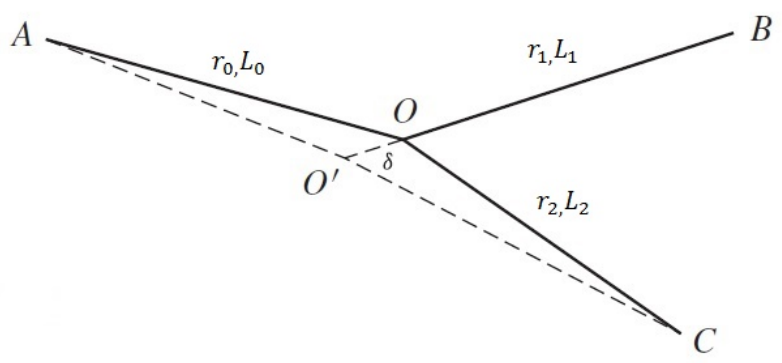

Gambar 4. Perubahan kedua pada konfigurasi pembuluh darah yang bercabang dua

Selanjutnya, Gambar 4 adalah perubahan kedua pada konfigurasi pembuluh darah yang bercabang dua. Dari Gambar 4 diperoleh pajang dari $O^{\prime} B$ sebagai berikut.

$$
O^{\prime} B=L_{1}+\delta
$$

Dengan cara yang sama pada kasus sebelumnya diperoleh panjang dari $O^{\prime} A$ dan $O^{\prime} C$ sebagai berikut :

$$
\begin{aligned}
& O^{\prime} A=L_{0}-\delta \cos \theta, \\
& O^{\prime} C=L_{2}+\delta \cos (\theta+\phi) .
\end{aligned}
$$

Dengan melakukan hal yang sama dengan prinsip sebelumnya, diperoleh

$$
r_{1}^{2}=r_{0}^{2} \cos \theta-r_{2}^{2} \cos (\theta+\phi) .
$$

Terakhir Gambar 5 adalah perubahan ketiga pada konfigurasi pembuluh darah yang bercabang dua.

Dari Gambar 5 diperoleh panjang dari $O^{\prime} C$ sebagai berikut :

$$
O^{\prime} C=L_{2}+\delta \text {. }
$$

Dengan melakukan cara yang sama dengan sebelumnya, diperoleh sebagai berikut

$$
\begin{aligned}
O^{\prime} A & =L_{0}-\delta \cos \phi, \\
O^{\prime} B & =L_{1}+\delta \cos (\theta+\phi) .
\end{aligned}
$$

Selanjutnya akan digunakan Persamaan 3.9. Selanjutnya diperoleh :

$$
r_{2}^{2}=r_{0}^{2} \cos \phi-r_{1}^{2} \cos (\theta+\phi) \text {. }
$$




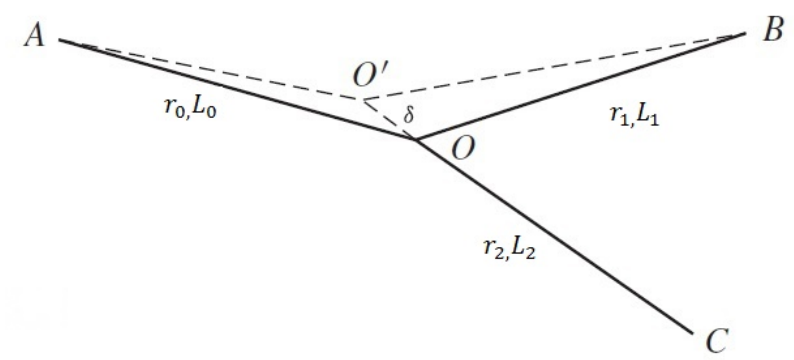

Gambar 5. Perubahan ketiga pada konfigurasi pembuluh darah yang bercabang dua

Dari persamaan (3.10), (3.11) dan (3.12) diperoleh nilai dari $\cos \theta, \cos \phi$ dan $\cos (\theta+\phi)$ sebagai berikut :

$$
\begin{aligned}
\cos \theta & =\frac{r_{0}{ }^{4}+r_{1}{ }^{4}-r_{2}{ }^{4}}{2 r_{0}{ }^{2} r_{1}{ }^{2}} . \\
\cos \phi & =\frac{r_{0}^{4}+r_{2}{ }^{4}-r_{1}{ }^{4}}{2 r_{0}{ }^{2} r_{2}{ }^{2}} . \\
\cos (\theta+\phi) & =\frac{r_{0}^{4}-r_{1}{ }^{4}-r_{2}{ }^{4}}{2 r_{1}{ }^{2} r_{2}{ }^{2}} .
\end{aligned}
$$

Menurut John Adam [1], untuk aliran yang optimal pada suatu pembuluh darah tunggal, laju aliran $f$ sebanding dengan pangkat tiga radius. Ketika aliran pada percabangan pembuluh darah dibagi menjadi dua bagian, yang berarti $f_{0}=f_{1}+f_{2}$, maka hubungan antar radius menjadi

$$
r_{0}{ }^{3}=r_{1}{ }^{3}+r_{2}{ }^{3} .
$$

Persamaan (3.13), (3.14) dan (3.15) akan akan digunakan untuk membuktikan observasi Empiris Roux.

Teorema 3.1. Hukum Empiris Roux Pertama Pembuluh darah dengan radius yang sama juga mempunyai sudut percabangan yang sama terhadap pembuluh utama.

Bukti. Misalkan $r_{1}=r_{2}$, yaitu dengan mengganggap pembuluh darah primer memiliki percabangan yang sama. Berdasarkan Persamaan (3.13) dan persamaan (3.14), diperoleh

$$
\cos \theta=\frac{r_{0}^{4}}{2 r_{0}^{2} r_{1}^{2}} ; \quad \cos \phi=\frac{r_{0}^{4}}{2 r_{0}^{2} r_{1}^{2}} .
$$

Karena nilai $\cos \theta=\cos \phi$, dapat disimpulkan bahwa $\theta=\phi$. Sehingga Hukum Empiris Roux Pertama terbukti.

Teorema 3.2. Hukum Empiris Roux Kedua Cabang pembuluh darah yang radiusnya lebih besar menghasilkan sudut yang lebih kecil daripada pembuluh darah yang radiusnya lebih kecil. 
Bukti. Misalkan $r_{2}<r_{1}$, artinya $r_{2}=\alpha r_{1}$ dengan $0<\alpha<1$. Jadi persamaan 3.13 dan persamaan 3.14 menjadi:

$$
\cos \theta=\frac{r_{0}^{4}+r_{1}^{4}\left(1-\alpha^{4}\right)}{2 r_{0}^{2} r_{1}^{2}} ; \cos \phi=\frac{r_{0}^{4}+r_{1}^{4}\left(1-\alpha^{4}\right)}{2 \alpha^{2} r_{0}{ }^{2} r_{1}^{2}} .
$$

Berdasarkan persamaan di atas apakah mungkin untuk menentukan mana dari kedua sudut $\theta$ dan $\phi$ yang lebih besar? Untuk sudut pada $(0, \pi / 2)$ misalkan $\theta$ adalah sudut yang dibentuk oleh cabang dengan radius $r_{1}$ dan $\phi$ adalah sudut yang dibentuk oleh cabang dengan radius $r_{2}$ dan $r_{1}>r_{2}$. Kemudian akan ditunjukkan $\theta>\phi$. Karena $0<\alpha<1$ maka

$$
\begin{aligned}
\frac{r_{0}^{4}+r_{1}^{4}\left(1-\alpha^{4}\right)}{2 \alpha^{2} r_{0}^{2} r_{1}^{2}} & <\frac{r_{0}^{4}+r_{1}^{4}\left(1-\alpha^{4}\right)}{2 r_{0}^{2} r_{1}^{2}} \\
\cos (\phi) & <\cos (\theta) .
\end{aligned}
$$

Akibatnya $\theta<\phi$. Jadi untuk $\theta, \phi \in(0, \pi / 2)$, terbukti $\theta<\phi$.

Teorema 3.3. Hukum Empiris Roux Ketiga Pembuluh darah dengan radius menuju nol memiliki cabang dengan sudut yang mendekati $90^{0}$.

Bukti. Misalkan $r_{2} \ll r_{1}$, artinya $r_{2}=\alpha r_{1}$ dengan $\alpha \ll 1$, sehingga diperoleh :

$$
\begin{aligned}
\cos \phi & =\frac{r_{0}^{4}+r_{1}^{4}\left(1-\alpha^{4}\right)}{2 \alpha^{2} r_{0}^{2} r_{1}^{2}} \\
& =\frac{\left(1+\alpha^{3}\right)^{4 / 3}-1+\alpha^{4}}{2 \alpha^{2}\left(1+\alpha^{3}\right)^{2 / 3}} .
\end{aligned}
$$

Untuk cabang dengan sudut $\phi=70^{\circ}$, diperoleh $\alpha \approx 0.407$; dan jika $\phi=80^{\circ}$ maka $\alpha \approx 0.2246$. Jelas, ini menunjukkan bahwa sudut percabangan semakin besar ketika radius pembuluh darah semakin mengecil, artinya sudut cabang mendekati $90^{\circ}$ karena radius pembuluh darah menuju 0. Sehingga Hukum Empiris Roux ketiga terbukti.

Dengan demikian persamaan (3.13), (3.14) dan (3.15) pada model konfigurasi pembuluh bercabang dua dapat menjelaskan ketiga Hukum Empiris Roux.

\section{Kesimpulan}

1. Dari pemodelan yang telah dilakukan, diperoleh biaya minimum pada aliran fluida sebagai berikut :

$$
\mathcal{L} \equiv L_{1} A_{1}+L_{2} A_{2}=(c-b \cot \theta) A_{1}+b \csc \theta A_{2},
$$

dengan $A_{1}=\left(\frac{k}{r_{1}^{4}}+K r_{1}^{2}\right)$ dan $A_{2}=\left(\frac{k}{r_{2}^{4}}+K r_{2}^{2}\right)$, sehingga diperoleh sudut yang meminimumkan $\mathcal{L}$ adalah $\theta=\cos ^{-1}\left[\left(\frac{r_{2}}{r_{1}}\right)^{4}\left(\frac{k+K r_{1}^{6}}{k+K r_{2}^{6}}\right)\right]$.

2. Pada kasus pembuluh darah tunggal didapat model sebagai berikut :

$$
\mathcal{L}=k L r^{-4}+K L r^{2},
$$

dengan nilai yang meminimumkan $\mathcal{L}$ adalah $r=\sqrt[6]{\frac{2 k}{K}}$. 
3. Pada kasus pembuluh darah bercabang dua diperoleh model sebagai berikut

$$
\mathcal{L}=\mathcal{L}_{\mathcal{A O}}+\mathcal{L}_{\mathcal{O B}}+\mathcal{L}_{\mathcal{O C}},
$$

dimana nilai minimum $\mathcal{L}$ diperoleh ketika ketiga persamaan berikut terpenuhi :

$$
\begin{aligned}
\cos \theta & =\frac{r_{0}{ }^{4}+r_{1}{ }^{4}-r_{2}{ }^{4}}{2 r_{0}{ }^{2} r_{1}{ }^{2}} . \\
\cos \phi & =\frac{r_{0}^{4}+r_{2}{ }^{4}-r_{1}{ }^{4}}{2 r_{0}^{2} r_{2}^{2}} . \\
\cos (\theta+\phi) & =\frac{r_{0}^{4}-r_{1}{ }^{4}-r_{2}{ }^{4}}{2 r_{1}^{2} r_{2}{ }^{2}} .
\end{aligned}
$$

4. Dengan menggunakan model pada konfigurasi pembuluh darah bercabang dua diperoleh kesesuaian model dengan observasi hukum Empiris Roux.

\section{Ucapan Terima kasih}

Terima kasih kepada ibu Dr. Haripamyu, ibu Dr. Des Welyyanti, serta ibu Dr. Susila Bahri selaku dosen penguji, yang telah memberikan kritik dan saran dalam penulisan makalah ini.

\section{Daftar Pustaka}

[1] Jhon. A. Adam. 2011. Blood Vessel Branching : Beyond The Standard Calculus Problem. Math Mag. 84:196-207

[2] Bartle, Robert G., dan Donald R. Sherbert. 2011. Introduction to Real Analysis. Edisi ke-4. John Wiley and Son, Urban-Champaign.

[3] A. C. Burton. 1965. Physiology and Biophysics of the Circulation. Year Book Medical Publishers, Inc

[4] R. Rosen. 1967. Optimality Principles in Biology. Butterworth, London

[5] W. Roux. Doctoral Thesis on the Bifurcation of Blood Vessel, by Thompson.

[6] D'Arcy W. Thompson. 1992. On Growth and Form. Dover, New York

[7] Varberg, Purcell, and Rigdon. 2004. Kalkulus Jilid 1, Edisi 8. Penerbit Erlangga, Jakarta

[8] M. Zamir. 1988. The Branching Structure of Arterial Trees. Comments on Theoretical Biology 1:15-37 